\title{
CATALUÑA Y LOS INICCIOS \\ DE LA PRENSA PERIÓDICA \\ EN ESPAÑA
}

Jaume Guillamet

Universitat Pompeu Fabra (Barcelona) 



\section{INTRODUCCIÓN}

La acción de los gobiernos tiene decisiva influencia en la oportunidad, fuerza y rapidez con que aparece y se desarrolla la prensa periódica bajo el Antiguo Régimen. El notorio retraso español en la publicación de gacetas oficiales y periódicos literarios — generalizada ya en el siglo XVII en Francia e Inglaterra y en el mosaico político de lo que será Alemania- se debe tanto al absolutismo cerril de la monarquía de los Austrias como al tradicionalismo imperante en la sociedad española de la época, sometida aún por un siglo más a la vigilancia y dictado de la Santa Inquisición. No es una mera casualidad que la primera publicación periódica conocida en la península - Gazeta (1641), en Barcelona, bajo dominación francesa - sea una traducción al catalán de la Gazette semanal de París, autorizada diez años antes por Luis XIII a Teophraste Renaudot.

Cuando en 1697 la Gaceta de Madrid pasa de mensual a semanal —-treinta y seis años después de su primer precedente, Gaceta Nueva (1661)—, en Inglaterra ya se ha estrenado la libertad de imprenta que España aún va a tardar más de un siglo en conocer. La acción del gobierno será un claro factor de atraso en el desarrollo de la prensa hasta el cuarto decenio del siglo XIX, con dos breves excepciones liberales. Durante el siglo XVII el número de periódicos es muy escaso y durante el XVIII apenas alcanzarán a tenerlos de manera relevante media docena de ciudades.

Podrían tenerse en cuenta otros factores para explicar ese atraso, tanto más relevante porque España es aún la cabeza de un imperio —el mayor del mundo en extensión-, pero la acción del gobierno, renuente a los nuevos aires políticos y culturales que anuncian la Ilustración francesa, es el más determinante. El tradicionalismo nobiliario y religioso de las clases dirigentes no impedirá el surgimiento de iniciativas modernizadoras en el campo cultural y en el informativo 
en los breves períodos de apertura a las nuevas corrientes del pensamiento, en especial bajo el reinado de Carlos III (1759-1788), la mayoría de las cuales tiene escasa duración.

La expresión de "primera edad de oro" de la prensa española (Guinard, 1973; 125-150), con que se ha valorado la elevada calidad de los periódicos aparecidos en los decenios centrales del XVIII, acentúa aún más el contraste con una larga y prosaica edad de hierro que alcanza hasta el estallido de la Guerra de la Independencia (1808-1814) y que se restablecerá aún por dos veces al final de ésta y del Trienio Constitucional (1820-1823), hasta la muerte del rey Fernando VII en $1833 .{ }^{1}$

\section{PRENSA DE LA CORTE}

La lentitud con que se imitaron los modelos franceses de prensa de Estado es compartida por las casas de Austria y de Borbón, que, en el paso del siglo XVII al XVIII, se relevaron en la titularidad de la corona. El retraso en la aparición de una gaceta oficial de la monarquía — cuya creación se atribuye a la ambición personal de Juan José de Austria, hijo natural de Felipe IV, más que a la propia acción de gobierno- es comparable al del Diario de Literatos (1737-1738) en Madrid, efímera imitación del Journal des Savants, creado en París en 1660. El rey que lo autorizó, Felipe V — nieto de Luis XIV y primer Borbón español一, ya se había distinguido por el reconocimiento y nuevo impulso dado a la Gaceta de Madrid en 1701 y, más tarde, por completar el desarrollo del modelo francés con la creación del Mercurio Histórico y Político (1735-1784), después Mercurio de España, inspirado en el Mercure de France, redefinición política en 1724 del antiguo Mercure galant de 1672.

En este contexto, la aparición de publicaciones impresas en otras ciudades distintas de Madrid quedaba forzosamente limitada a publicaciones no periódicas como las relaciones de sucesos — peldańo anterior y origen de las gacetas semanales (Ettinghausen, 1992, 12-70), pero género autónomo y de extensa vida, desde

\footnotetext{
${ }^{1}$ Los datos nuevos aportados por el autor en este artículo corresponden a una investigación reciente sobre los orígenes de la prensa en Cataluña reseñada en la bibliografía (Guillamet, 2003a), por lo que se ahorran anotaciones en el texto.
} 
finales del siglo XV hasta bien entrado el XIX - y reimpresiones de la Gaceta de Madrid, autorizadas a impresores locales ${ }^{2}$.

Excepción institucional es la Gazeta de Barcelona (1706-1714), publicada en los últimos tiempos como Diario del sitio y defensa de Barcelona, creada por el pretendiente Carlos de Austria durante la Guerra de Sucesión en oposición a la Gaceta de Madrid de Felipe V. En los décadas inmediatamente anteriores, Barcelona había ofrecido de manera excepcional la publicación simultánea de hasta cinco gacetas semanales más, en un régimen más abierto de libertad de impresión que diferenció la Corona de Aragón del Reino de Castilla hasta la Nueva Planta de $1715^{3}$.

Durante el siglo XVIII, la reimpresión barcelonesa de la Gaceta de Madrid, autorizada por el rey a sus impresores locales, presenta una aparente autonomía nominal —Noticias de diferentes partes venidas a Barcelona (1716-1750), Gaceta de Barcelona (1750-1762), Gazeta de Barcelona (1762-1806)—, pero su supresión por real orden para favorecer la explotación económica de la Gaceta de Madrid es fiel expresión de su carácter subdisiario.

La primera prensa periódica española es privativa de la Corte. La reedición o reimpresión de la gaceta y de los periódicos literarios en otras ciudades fue casi la única forma de extensión de la prensa periódica hasta muy entrado el siglo XVIII. El impulso para una prensa propia de las principales ciudades parece ligado a la creación, en 1758, del conocido como Diario noticioso ${ }^{4}$ de Nipho, cuyo modelo de periodismo local de divulgación cultural y de servicios despertará el interés de numerosos imitadores, el más afortunado de los cuales será el bicentenario Diario de Barcelona, aparecido en 1792.

El factor territorial adquiere relevancia en el primer desarrollo de la prensa española en la segunda mitad del siglo XVIII. Si bien el número de publicaciones

\footnotetext{
${ }^{2}$ En Cataluña, hallamos ejemplos en pequeñas ciudades como Gerona (1787-1800), Vic $(1803,1805)$ y Tortosa (1808), con gacetas que llevan el nombre de la población y son reimpresiones de la de Madrid.

3 Se trata de cinco series de gacetas semanales que presentamos con la abreviación de los títulos y mención de los ańos de ejemplares conocidos: Noticias Generales de Europa (Correo de Italia) (1684, 1687, 168990), Noticias Generales de Europa (Correo de Flandes) (1684-93, 1695-98, 1701-02), Noticias Generales de Europa (Correo de Francia) (1686-1690), Gazeta (Correo de España) (1701-1702), Gazeta (Correo de Francia) (1700-1701).

${ }^{4}$ Diario noticioso, curioso-erudito y comercial, público y económico, 1759, que toma en 1788 el título de Diario de Madrid. Nipho se había desvinculado en 1759 para entregarse a otros proyectos, entre los que suele destacar especialmente el semanario El Caxón de Sastre (Sáiz, 1983, 222-237)
} 
de la Corte continúa siendo más alto que el resto — 139 frente a 106, entre 1759 y $1808^{5}$-, el impulso de la prensa en las principales ciudades es la novedad de estos años, donde se dan además diversos casos de solicitudes denegadas por un gobierno arbitrario que actuaba con total discrecionalidad. Como las de Madrid, la mayoría son publicaciones efímeras. Es notable la coincidencia temporal —en ciudades como Sevilla, Cádiz, Granada, Málaga, Murcia, Cartagena, Valencia, La Laguna (Canarias), Pamplona, Salamanca, Valladolid y Palma de Mallorca, además de Barcelona, pero no aún en ninguna ciudad gallega- de numerosas iniciativas inspiradas en el modelo informativo local del Diario noticioso, probablemente la aportación más genuina del primer periodismo español.

Será frecuente la adopción del nombre de Diario - con una vocación cotidiana alejada del mensual Diario de los Literatos de España del reinado de Felipe $\mathrm{V}$ - , aun cuando en ocasiones se trate de periódicos semanales, como en el caso del célebre Diario Pinciano de Valladolid (1787-88), en cuyo Plan del Diario ofrece José Mariano Beristain un programa que podrían suscribir todos ellos, partidario de ofrecer regularmente "el estado de actividad y de ilustración" de las ciudades. Aún sujetos a la arbitrariedad de la autorización real y a la frecuente indiferencia social, cuando no incomprensión o rechazo, esos primeros editores locales, pese a la limitación forzada de sus objetivos a la divulgación cultural y a los avisos, dejan constancia de un espíritu ilustrado y un propósito reformador, una "voluntad enciclopedista, la tímida aparición de temas importantes, (que) testimonian el lento progreso del espíritu "filosófico" a través de la península" (Guinard, 1973, 364).

Indicios más o menos explícitos de ese espíritu innovador han sido apreciados en la mayor parte de estos periódicos, lo cual muestra también a nivel local el protagonismo de sectores sociales avanzados, aun cuando muy reducidos, en el primer impulso de la prensa espańola, en sorda pugna con el poder del Estado y la vigilancia de la Inquisición y de la propia sociedad española, poco receptiva a las ideas nuevas de la Ilustración.

Los diarios literarios a la francesa del reinado de Felipe $\mathrm{V}$ y los periódicos morales a la inglesa del de Carlos III han de publicarse en Madrid, en la Corte,

5 Cifras calculadas para los reinados consecutivos de Carlos III y Carlos IV (Domergue, 1981, 82; Sáiz, 1983, 248-263) 
"de donde salen para todos los Pueblos de la Península los rayos de sol, que en todas partes necesitan las Ciencias, y (porque) allí esté el corazón de donde se deriva el vigor u el movimiento, que han de menester las Artes", como escribe Beristain. Pero "también es cierto que cada Capital de provincia debe ser un globo de luz, que disipe las sombras del error, de la preocupación, y de la ignorancia en su pequeña esfera, y que como una fuerza inmediata, aliente, vivifique, y de actividad a todos los miembros de su respectivo Cuerpo". La subordinación de Barcelona a la prensa de la Corte durante todo el siglo XVIII ${ }^{6}$, en contraste con el desarrollo social y económico de Cataluña, ha sido motivo de extrañeza para los estudiosos (Torrent y Tasis, 1964, 31; Guinard, 1973, 83; Sáiz, 1983, 254).

La salvedad hecha de los primeros diarios locales en la prohibición general de publicaciones periódicas dictada en 1792 — como "cordón sanitario" protector de la penetración de las ideas de la Revolución francesa-, que siempre se ha interpretado como un reconocimiento de su inocuidad política, lo es también de su importancia social y económica.

\section{PRENSA LOCAL}

En el arranque de los diarios locales de finales del siglo XVIII, aun siguiendo la estela del Diario de Madrid, predominan los factores sociales sobre los políticos. Más que Nipho en la capital, se dan cuenta sus promotores del interés de la prensa como medio de comunicación al servicio de la vida local. El servicio que el creador del primer diario español —un siglo más tarde que los alemanes de Leipzig; medio que el Daily Courant de Londres ya en régimen de libertad de imprenta y de circulación de todo tipo de noticias; veinte años avanzado al primer Journal de Paris - plantea para los viajeros y transeúntes de paso por la Corte lo formulan sus émulos en Sevilla, Valencia y Barcelona para el público estable de estas ciudades en función de las noticias relativas a sus negocios y relaciones cotidianas.

\footnotetext{
${ }^{6}$ Además de la reimpresión citada de la Gaceta de Madrid, los únicos títulos publicados en Barcelona en estos años, a excepción de los primeros diarios, son El Duende especulativo sobre la vida civil en Madrid (1761), El Caxón de Sastre Catalán $(1761,1764)$ y el Semanario Curioso, Erudito, Comercial y Económico (1773), todos ellos basados en la reimpresión o reproducción de periódicos madrileños.
} 
Los primeros intentos barceloneses a cargo de Pedro Ángel de Tarazona, ensombrecidos por el éxito posterior y la larga trayectoria del Diario de Barcelona, son muy relevantes a los efectos de comprender el factor social y económico latente en la primera expansión territorial de la prensa. Tarazona es conocido como un agente de negocios y como tal veía la introducción de la prensa periódica en la capital de Cataluña. Por dos veces trató de crear un periódico como el creado por Madrid, cuya fórmula trató de explotar en Barcelona de acuerdo con los socios de Nipho. A la denegación real de esa solicitud siguió la autorización del Diario curioso, histórico, erudito, comercial, público y económico (1762), que no alcanzó sus objetivos y hubo de cerrar al cabo de cuatro meses. Diez años después insistió con el Diario evangélico, histórico-político (1772), pronto cambiado a Diario curioso, histórico, erudito, comercial, civily económico (1772-73), que duró ocho meses. Promovió, además, otras publicaciones inspiradas en las de la Corte: El Caxón de Sastre Catalán (1761, 1764) —reedición adaptada del Caxón de Sastre de Nipho, única ocasión en que parece haberle acompañado el éxito-y el Semanario Curioso, Erudito, Comercial y Económico (1773).

Tarazona había dejado muy claro el orden de importancia entre las dos partes en que iba a dividir el Diario:

Dos asuntos ha de contener esta diaria tarea, el uno ha de ser lo curioso, Histórico, Moral y Erudito; y el otro lo Comercial, Público y Económico. Para este segundo, que es el principal objeto, debe mediar mucho más la fatiga personal, diligencia y eficacia, que la literatura. Para el primero, que sólo ha de servir de adorno y suplemento al segundo...

La nula respuesta de los comerciantes, artesanos y ciudadanos en general a su oferta de publicación de todo tipo de avisos le obligó a emplearse a fondo en la elaboración de la primera parte, la menos importante, pero imprescindible para mantener el proyecto en pie. Entre los cuatro apartados de que consta - religioso, histórico, militar y científico- - y que ofrece en días sucesivos, destaca su atención por la divulgación de la historia de Cataluña:

las acciones mas ilustres en Letras y Armas de la Nacion Cathalana, porque es mas conforme a razon y apeteceran mas que se les instruya antes en las glorias de su País, y de sus Progenitores, que no en las de los agenos; de lo qual, sin duda, se originará al Público el gran beneficio racional de que se vayan inclinando al buen gusto de leer la Historia de su Patria. 
Tarazona compara su propósito con la tarea divulgadora de la historia de Inglaterra que lleva a cabo Boyle en la prensa de Londres,

con el loable fin de que las gentes mas pobres y apartadas del conocimiento de las Ciencias pudiesen facilmente introducirse con fruto en la Historia de su Patria, y yo no considero a los Cathalanes con menos inclinacion para esto mismo que los Ingleses.

El propósito instructivo y divulgador de la primera prensa local va ligado a la búsqueda de un público al que no han llegado aún las gacetas ni los periódicos literarios.

Mi fin es instruir a los que menos saben, para que no ignoren tanto y darles en estilo llano, perceptible, y acomodado a la capacidad de todos unas preciosas porciones de caudal oculto en las minas de las ciencias, sin que hallen fastidio y desabrimiento quando lean assumptos agenos de su inclinacion y distantes de su genio.(...).

Aqui vamos a instruir al indocto, y al menos Sabio. La fortuna puede negarnos las conveniencias: Como no nos falte la sabiduría, podemos perdonarselas. El acomodado ignorante es mucho menos que un pobre; pues si no es docto, o a lo menos inclinado a saber, y a las bellas Letras y Artes, que le importa ser acomodado?

Se trataba de un público con la capacidad económica adecuada a la adquisición de esos primeros periódicos, financiados únicamente por los suscriptores, aunque de escasa formación cultural, como se encargaron de señalar quienes ridiculizaron la utilización de las peluquerías como puntos de venta, no sólo de las librerías. "Peluquero" era el séptimo título que añadía al nombre del Diario, en 1795, el literario Correo de Gerona. ${ }^{7}$ Veinte años más tarde el fundador del Diario de Barcelona, Pedro Pablo Husón de Lapazaran ${ }^{8}$, redactó con la ex-

7 Editado por José Felipe Olivé, durante la estancia del ejército en la frontera durante la guerra contra la Revolución francesa (1793-1795, conocida en Cataluña como la Guerra Gran), es el único periódico literario catalán del siglo XVIII, influenciado por el Semanario literario y curioso de Salamanca (1793-1797).

${ }^{8}$ Esta es la forma que Husón utilizó en varias ocasiones para escribir su nombre en el Diario de Barcelona, de forma que nos parece la más adecuada, a pesar de que pueda encontrarse escrito en otras obras como Ussón, Usón o Hussón y Lapezarán o Lepazarán. 
tensión necesaria un programa parecido al de Tarazona, que sintetizó gráficamente:

Esta es una obra que tratando por su objeto todo género de asuntos y hallándose por su pequeño coste en las manos de toda clase de personas, coopera más que otra alguna a la general instrucción y a la común utilidad.

Los diarios locales están al servicio de "la general instrucción y la común utilidad". Ese es el alcance de su novedad, aunque las afirmaciones de su editor en relación con su precio y con su público hay que ponerlas en el contexto de la época.

La respuesta ciudadana fue en este caso inmediata y el gran número de avisos y "noticias particulares de Barcelona", según encabezamiento dado por Husón a la segunda parte, pronto deshizo el equilibrio inicial en el contenido del periódico. Aparecido el día 1 de octubre de 1792, el Diario de Barcelona puso desde el día siguiente al menos la mitad de sus cuatro páginas a esa estratégica segunda parte, que ocupó por primera vez toda su extensión el día 31 de enero de 1793, al cabo de cuatro meses justos de su aparición. Excepcionalmente apareció ese día el diario sin la primera parte, cosa que a partir de 1798 tomaría carta de normalidad.

Durante los primeros años, Husón dio un alto nivel a su periódico y un primer desarrollo al periodismo cultural y científico, con la colaboración de escritores barceloneses en todos los ámbitos. Destaca entre ellos el médico Francisco Salvá Campillo, una de las personalidades más avanzadas de la ciencia española, promotor de la línea de telégrafo óptico Madrid-Aranjuez, entre otras y muy diversas iniciativas. Publicaba desde 1786 unos "Diarios meteorológicos" en el Memorial literario de Madrid y se hizo cargo de las observaciones astronómicas y meteorológicas que sirvió cada día al Diario de Barcelona hasta su muerte en 1827, durante 35 años. Pero la base del éxito del primer diario barcelonés en conseguir una publicación continuada - y el tercero en el orden de aparición, no el primero como se suele creer y escribir - radica en su sección de avisos oficiales y noticias particulares del comercio, la industria y la navegación, oficios religiosos y sesiones corporativas, ventas de libros y anuncios de las representaciones teatrales, las ofertas y demandas de empleo e intercambio, compras y ventas, intereses de las familias y de los individuos. 
Con razón, Tarazona considera esta parte la más importante de un diario, porque era la que lo hacía necesario al público. Husón obtiene la respuesta positiva del público de Barcelona y cuesta establecer hoy, con los datos disponibles, la razón de los fracasos del primero. El creador del Diario de Barcelona cuenta con la experiencia de haber sido oficial mayor del Diario de Madrid —mérito específico que avaló ante el Rey Carlos IV la solicitud de autorización y privilegio real, además de su antigua pertenencia a la Corte, a la que llegó con el rey Carlos III desde Nápoles - tras su relanzamiento en 1786 por el francés Jacques Thevin, incorporando la experiencia del Journal de Paris, aparecido en 1777.

Se ha hablado de un acuerdo comercial (Laguna, 2001, 30-49) entre Thevin y Husón, que incluiría también a José María de Lacroix, creador del Diario de Valencia (1792-1835), del Diario Histórico y Político de Sevilla (1792-93) y de El Correo del Postillón (1794) en Cádiz, unidos por el origen francés de los tres editores y la recepción mutua de suscripciones, así como la propia implantación de estas como forma de relación con el público más segura para el editor que la venta de ejemplares al número. La incorporación del nombre de las ciudades al título de los periódicos, con los datos astronómicos y meteorológicos en la primera página, sería también de este momento. La llegada de editores franceses como Thevin y Lacroix confirma la fuerza de los factores sociales y territoriales en el primer desarrollo de la prensa española.

\section{PRENSA POLÍTICA}

Hasta la reacción contra la invasión napoleónica de 1808 no se invertirá el sentido de la influencia de los factores políticos. Con la libertad de imprenta de facto que se deriva de la insurrección general al paso de las tropas francesas desde las fronteras de los Pirineos hacia Madrid y Portugal — presunto objetivo de la operación aceptada por el rey Carlos IV_-, las juntas locales y provinciales pueden disponer bajo su responsabilidad de la edición de periódicos y en pocos meses se multiplican en gran número. Con los pasos siguientes - establecimiento oficial de la libertad de imprenta por el decreto de noviembre de 1810 y su consagración solemne en la Constitución de 1812 - España estrena un régimen de libre expresión política y periodística del que únicamente disponen la Gran Bretaña y los Estados Unidos de América, ya que en Francia la prensa de la revolución ha 
sido sometida de nuevo por Napoleón a los rigores de la autorización previa y de la censura.

El estreno español de la libertad de imprenta — que alcanza gran intensidad en Madrid, Sevilla, Cádiz y Mallorca' donde la prensa se multiplica en número de cabeceras y de ciudades pero goza de un pluralismo muy ajustado - incluso después de entrar en vigencia la Constitución-, a causa de ser escenario permanente de las acciones de guerra.

El Diario de Barcelona se pone voluntariamente al servicio del invasor, antes de ser incautado y administrado directamente por éste: en marzo de 1810, como Diari del Gobern de Cataluña y de Barcelona, bilingüe catalán-francés hasta septiembre, y como Diario del Gobierno de Cataluña y de Barcelona, bilingüe castellano-francés, hasta marzo de 1814. En Gerona, ocupada desde diciembre de 1809, se editan también periódicos franceses, entre ellos la Gaseta del Corregiment de Girona (1810), bisemanal, primer periódico íntegramente en catalán, durante un breve período de gobierno "particularista".

La administración francesa publicó hasta 7 periódicos en 3 poblaciones - Barcelona, Gerona y Figueres - frente a otros 30 periódicos publicados en otras 10 poblaciones — además de Gerona — por las autoridades catalanas y algunos editores privados. Otros cinco periódicos en zona española, de los que sólo hay referencias bibliográficas, elevarían el número total a 42, frente a los más de 300 estimados para toda España (Fuentes y Fernández Sebastián, 1996, 52-57). Como una paradoja de la historia, la prensa bajo dominio francés no se publica en régimen de libertad ni sus editores son ajenos a la administración. Del lado español, sólo la Gazeta Militar y Política del Principado de Cataluña (1808-13) de la Junta Superior del Principado de Cataluña tiene carácter de publicación oficial, así como la Gazeta de Cataluña (1813-14) de la Diputación General de Cataluña que la sucedió. El resto — la mayoría de ellos, diarios en Cervera, Gerona, Lérida, Manresa, Reus, Tarragona y Vic_- dependen de las juntas locales o son autorizados por éstas a impresores o editores particulares.

Aun cuando el nivel de pluralismo alcanzado por la prensa catalana es escaso, excepto en Reus y en Vic, en los últimos meses de la guerra, la libertad de impren-

\footnotetext{
9 En esta isla alejada de los escenarios de la guerra, la lucha entre liberales y serviles a través de la prensa alcanza especial virulencia (Seoane, 1987, 57).
} 
ta de facto se produce sobre todo en la circulación de noticias. La ruptura con el rígido monopolio oficial de las gacetas sobre las noticias políticas y militares es debida a la fragmentación administrativa y de las comunicaciones, que favorece la función informativa de los nuevos diarios locales, y a la propia incapacidad de la Gazeta Militar y Política del Principado de Cataluña - que llega a publicarse en más de doce sedes distintas, siguiendo a la Junta Superior y al cuartel general del Ejército- de cubrir plenamente sus funciones. Si bien las noticias de otras partes de Espańa llegan con retrasos de varias semanas a causa de las dificultades de la guerra, la observación de los nombres de los periódicos citados como fuentes de información por la prensa catalana de esos años revela un intenso intercambio y un uso igualmente extenso de la prensa francesa como fuente de información. Un dato a subrayar es la publicación en verano de 1808 de un llamado Diario de Igualada, probablemente número único e impreso en Cervera, en clave irónica, que ensaya un periodismo de humor de gran calidad.

La elaboración de noticias políticas y militares, hasta el momento reservadas al celo oficial de los redactores de la Gaceta de Madrid, pasa a manos de los primeros periodistas locales. Como partícipes y testigos en ocasiones de los hechos de que informan, como receptores en otras de correspondencias no siempre fiables, en ambos casos se asiste en la lectura de esas páginas a los balbuceos históricos de la redacción informativa y del ejercicio responsable de asegurar a un tiempo la credibilidad no siempre garantizada de las noticias, así como a algunos episodios de conflicto sobre la prioridad de su publicación en las hojas informativas del ejército. Los artículos de opinión y las polémicas permanentes con la prensa francesa adolecen de un tono doctrinal, de un estilo retórico y de una sobrecarga argumentativa alimentada de notas históricas y acotaciones a pie de página anteriores a las formas de opinión periodística que podrán desarrollarse mejor algunos años más tarde.

El estreno de la prensa política de partido no se produce en Barcelona hasta el Trienio Constitucional (1820-23), casi cuatro ańos en los que por primera vez la capital de Cataluña conoce la publicación simultánea y la competencia de hasta cuatro diarios: Diario Constitucional, Politico y Mercantil de Barcelona (1820-23), El Indicador Catalán (1822-23) y Diario de la Ciudad de Barcelona o El Eco de la Ley (1822-23), además del ya veterano Diario de Barcelona, reaparecido en junio de 1814, al cabo de una breve suspensión, de la mano del impresor Antonio 
Brusi Mirabent. La multiplicación de periódicos es más intensa ya que alcanza el número de 46 - frente a unas 345 para toda España (Fuentes, 1994, 165196)_, en un total de diez poblaciones.

La expansión territorial resulta más limitada en ese segundo paréntesis liberal, ya que junto a las 24 publicaciones en Barcelona y otras 9 de Tarragona, los periódicos diarios y semanales registrados en Manresa (3), La Seu d'Urgell (2), Gerona (2), Vic (2), Reus (1) y Lérida (1) son de breve duración, además de publicaciones menores en Cervera (1) y Mataró (1). En una época de fuerte predominio de la prensa de Madrid — que difunde la mayor parte de sus ejemplares en el resto de España (Seoane, 1987, 17)—, se percibe la existencia de un mercado catalán en torno a la prensa de Barcelona, de forma más clara que en los primeros años del Diario de Barcelona, cuando su existencia estaba sujeta a la discrecionalidad del poder. Después de la descentralización espontánea y forzada de los ańos de la guerra de la Independencia, en las ciudades catalanas sólo se promueven de nuevo periódicos por el impulso político del jefe político de la provincia — Lérida, 1822—, de la sublevación realista —Manresa y La Seu d'Urgell, 1822 - o de la invasión francesa de apoyo a Fernando VII —Gerona y Vic, 1823. Solamente Tarragona ofrece un movimiento periodístico continuado e intenso, hasta hoy poco conocido, a lo largo de todo el Trienio. El desarrollo de la prensa en las ciudades medias queda para mediados de siglo y, para algo más tarde, el fenómeno de la prensa comarcal (Guillamet, 1983).

La brevedad y frustración de ambos paréntesis liberales dejará un poso de frustración ahogada por la dura represión ejercida en Cataluña durante el último período del reinado de Fernando VII por el capitán general Conde de Espańa, cuyo desprecio por la función de la prensa le llevó a humillar reiteradamente a Pablo Soler, editor del sumiso Diario de Barcelona desde la muerte de Brusi, en 1822, a causa de la fiebre amarilla. Dejaron también ambos ensayos de prensa liberal el poso necesario para su resurgimiento en 1833, con un nuevo cambio político, éste más suave y progresivo, para asegurar la sucesión del trono para la recién nacida Isabel II, frente a las pretensiones de Carlos María Isidro, el hermano del rey, aún más absolutista.

Hay una generación de relevo, encarnada en las personas de Ramón López Soler, primer director de El Vapor (1833-1839), y de su compañero en la revista El Europeo (1823) Buenaventura Carlos Aribau, que publica en las páginas del nuevo 
periódico el poema "Oda a la Pàtria”, símbolo fundacional de la Renaixença cultural catalana. Ni este periódico, patrocinado por el capitán general Manuel Llauder, ni los que le sucedan antes de la ley de libertad de imprenta de 1837, avanzarán tanto en la producción y redacción de noticias propias, como en la divulgación, la argumentación y del debate de las ideas liberales en política y economía. Quizá lo más interesante desde el punto de vista informativo sea la aparición progresiva de la figura del corresponsal propio - al que se refiere a menudo El Vapor y que ya se ha visto en El Indicador Catalán—, destacando entre las frecuentes correspondencias ocasionales que los periódicos venían recibiendo. En el terreno de la opinión, entre El Vapor y el Boletín del Comercio de Madrid se cruzaron ya en 1833 las primeras polémicas sobre los objetivos y necesidades de la dinámica economía industrial y comercial de Cataluña en el contexto de una Espańa fundamentalmente agraria.

La estabilización política de la función de la prensa derivada de la ley de imprenta y la Constitución de 1837 — superando el último intento de un liberalismo tutelado que significa el Estatuto Real de 1834- cierra definitivamente en España el primer gran período histórico del periodismo antiguo o artesano y abre la puerta al desarrollo de la prensa moderna o liberal, que en pocos años pondrá en pie las formas y estilos del periodismo en el que aún hoy nos reconocemos (Guillamet, 2003b).

\section{PRENSA DE EMPRESA}

A lo largo de ese período inicial de formación de la prensa en Cataluña se advierte un elemento estructural de continuidad en el Diario de Barcelona, a lo largo de cuatro etapas:

- 1792-1810: editado por el fundador Pedro Pablo Husón de Lapazaran;

- 1810-1814: incautado por la administración francesa;

- 1814-1821: editado por Antonio Brusi Mirabent, que ya en 1809 obtuvo la autorización de la Junta Superior del Principado de Cataluña, en reconocimiento de sus servicios a la causa espańola, previa retirada del privilegio a Husón por su colaboración con los ocupantes;

- 1821-1838: continuado por su viuda, con la colaboración de Pablo Soler, hasta que se hace cargo de la empresa el hijo Antonio Brusi Ferrer, quien estará a su frente hasta 1878 . 
Sólo a partir de 1833 vivirá el Diario — como se le conoció durante muchos años en la ciudad, hasta que comenzó a ser conocido como el diario de Brusi, para distinguirlo de los demás y, en especial, del diario de (José) Dorca, como se conocía al Diario Constitucional, durante el Trienio- una crisis importante de suscripciones que amenaza su supervivencia. Hasta entonces, el Diario había sido un negocio seguro, dado que fue casi siempre el único de Barcelona y de Cataluña y que el riesgo era nulo por la seguridad de la suscripción.

La Casa Brusi fue durante años la proveedora principal del Estado y del Ayuntamiento en librería, papelería e impresión, con la excepción relativa del Trienio Constitucional, durante el cual se llevó bien con los sectores liberales moderados y emprendió nuevos proyectos como el establecimiento pionero de la litografía en España, si bien sufrió el acoso político de otros impresores. De la solidez del negocio dan idea también los intentos de otros particulares y entidades de hacerse cargo del privilegio de edición del Diario, ya en 1814, apenas finalizada la guerra.

Fue probablemente la solidez del establecimiento lo que permitió al segundo Brusi, de regreso de un largo viaje por Europa, reconducir la dramática situación en la que encontró el Diario, aferrado a su viejo estilo de avisos locales, sin adaptarse a las nuevas exigencias del régimen liberal, con nuevos diarios arañándole un número de suscriptores cada vez más exiguo. La desaparición sucesiva de $E l$ Vapor y de El Constitucional $(1837,1839-1844)$ y la legislación restrictiva de prensa impuesta tras la regencia de Espartero y la proclamación de la mayoría de edad de Isabel II, permitieron a Antonio Brusi Ferrer dar una nueva época de esplendor al Diario de Barcelona, que hasta finales del siglo XIX ejerció una influencia importante en la vida española, por la solidez de su doctrina conservadora a la vez que por su tradición e independencia.

Con la adaptación a los nuevos factores políticos, no desatendería Brusi la línea de inocuidad política del antiguo diario local, favorecido por la reducción del espacio político de la prensa hasta la Revolución de 1868 y el Sexenio Democrático. No será hasta ese momento que deberá compartir la primacía del mercado con el republicano La Imprenta, nacido en 1858 como El Telégrafo, también con vocación de diario de empresa, convertido más tarde en El Diluvio, diario popular de amplia difusión hasta 1939. En realidad, Brusi Ferrer estuvo a punto de vender el Diario de Barcelona a Fernando Patxot y sólo al romperse el acuerdo al que ya habían llegado decidió éste la creación de El Telégrafo (Guillamet, 1996). 
En Madrid, no hay continuidad entre la prensa del Antiguo Régimen y la del liberalismo y predominan hasta mediados del siglo XIX los periódicos políticos, con la excepción de El Español (1835-37) del emigrado Andrés Borrego, inspirado en el modelo británico de The Times, fracasado al mezclarse en la lucha partidista (Seoane, 1987, 152-154). La renovación empresarial aportada por Las Novedades (1850-1872) y La Correspondencia de España (1859-1925) y confirmada, aun con orientación política por El Imparcial (1867-1936) y El Liberal (1879-1936), no evitó la fuerte politización de los diarios de la Corte.

En este contexto, la prensa catalana adquiere un perfil propio. Incluso alcanzando más adelante un pluralismo político más acentuado con la presencia periodística de las distintas corrientes catalanistas y del anarcosindicalismo, destacan la continuidad y el predominio del veterano Diario de Barcelona como "diario de empresa”, vocación que adoptarán sucesivamente el ya citado El Telégrafo y, en 1888, La Vanguardia, que había sido fundada en 1881 como órgano del partido liberal de Sagasta. El concepto de diarios de empresa no puede contemplarse en Cataluña como una mera novedad ligada a la industrialización de la información y al fenómeno de la prensa de masas, sino que hay que relacionarlo con los orígenes mismos de su tradición periodística. 


\section{BiBLIOGRAFÍA}

Domergue, L. (1981): Tres calas en la censura dieciochesca (Cadalso, Rousseau, prensa periódica), Toulouse, Université de Toulouse-Le Mirail.

Ettinghausen, Henry (1992): La guerra dels Segadors a través de la premsa de l'època, 4 volums, Barcelona, Curial.

Fuentes, Juan Franciso (1994): "Estructura de la prensa española durante el Trienio Liberal: Difusión y tendencias" en Trienio, revista de historia, 24, Madrid, p. 165-196.

Fuentes, Juan Francisco y Fernández Sebastián, Javier (1996). Historia del periodismo español, Madrid, Síntesis.

Guillamet, Jaume (1983): La Premsa Comarcal. Un model cátala de periodisme popular, Barcelona, Generalitat de Catalunya.

(1996): "El segon Brusi, la propietat del Diario de Barcelona i l'aparició de El Telégrafo" a Treballs de Comunicació, 8, p.153-168, Barcelona, Societat Catalana de Comunicació.

(2003a): Els origens de la premsa a Catalunya. Catàleg de periòdics antics (1641-1833), Barcelona, Arxiu Municipal de Barcelona.

(2003b): "Por una historia comparada del periodismo. Factores de progreso y atraso" en Doxa Comunicación, 1, p. 35-56, Madrid, Universidad CEU-San Pablo.

Guinard, Paul J. (1973): La presse espagnole de 1737 a 1791. Formation et signification d'un genre, Paris, Centre de Recherches Hispaniques.

Laguna Platero, Antonio (2001): Història de la comunicació a València, 1790-1898, Aldea Global, Universidades Autónoma y Pompeu Fabra de Barcelona, Jaume I de Castelló de la Plana y de Valencia.

Sáiz, Maria Dolores y Seonne, Maria Cruz (1983, 1987, 1996): Historia del periodismo en España, 3 vols., Madrid, Alianza Universidad.

Torrent, Joan y Tasis, Rafael (1964): Història de la premsa catalana, 2 vols., Barcelona, Editorial Bruguera. 